\title{
3 Research Square

\section{Thermally Induced Reduction of Hot Cracking Susceptibility in Electron Beam Welding of CuCr1Zr: A Numerical Approach}

R. Chin ( $\square$ ricardo.chin@tecnico.ulisboa.pt)

Universidade de Lisboa Instituto Superior Técnico: Universidade de Lisboa Instituto Superior Tecnico

P. S. Effertz

Graz University of Technology

\section{Pires}

Universidade de Lisboa Instituto Superior Técnico: Universidade de Lisboa Instituto Superior Tecnico

N. Enzinger

Graz University of Technology

\section{Research Article}

Keywords: Electron Beam Welding, Numerical Simulation, Thermomechanical coupling analysis,

Thermally induced reduction of the load, SimuFact Welding, Hot cracking

Posted Date: August 31st, 2021

DOl: https://doi.org/10.21203/rs.3.rs-783812/v1

License: (9) This work is licensed under a Creative Commons Attribution 4.0 International License.

Read Full License 


\section{Abstract}

Electron Beam Welding (EBW) is a highly effective and accurate welding process that is being increasingly used in industrial work and is of growing importance in manufacturing. In the current study, solidification cracking in EBW of a CuCr1Zr cylindrical geometry was explored. To investigate and prevent occurrence of hot cracking, a thermomechanically coupled numerical model was developed using Finite Element Method (FEM). An additional heat source was considered, in order to influence the resulting residual stress state, namely to minimize tensile stresses in the fusion zone during solidification. Hence, a methodical assessment of relevant parameters, such as the power, the diameter of the additional heat source and the distances between both heat sources was employed using Design of Experiments (DoE). It was found that for a particular parameter configuration, solidification cracking most likely could be averted.

\section{Introduction}

EBW is a fusion welding process where a narrow beam of electrons with high velocity is used to weld the two pieces of metals. The work pieces melt and partly evaporate as the kinetic energy of the electrons is transformed into heat upon interaction with the workpiece. The welding is usually carried out in vacuum to keep the energy density high [1]. Due to the high energy density, it can form a keyhole that results in deep and narrow welds. Thus, EBW remains indispensable in many aerospace, biomedical and mechanical applications namely due to a greater penetration depth, metallurgical purity of the weld, low heat input, small Heat Affect Zone (HAZ) and low susceptibility to deformation.

Over the past decade significant developments in modelling and simulation of the thermal cycle and the subsequent mechanical behaviour became very limited due to the inherent complexity of boundary conditions and the nonlinearity of material properties [2]. The development of numerical techniques like FEM has enabled researchers to overcome some practical difficulties such as complex boundary conditions, arbitrary geometry, and temperature dependent material properties [3]. Despite the technological innovations in FEM, there are still some problems when it comes to EBW, especially hot cracking. In order to solve this problem, other authors have tried to apply different experimental techniques, for instance, applying auxiliary heat sources on both sides of the weld to produce thermal gradients, and cooling elements under the weld to generate a specified temperature field altering the stresses occurring in the weld zone. However, such methodologies proved to be costly and time consuming [4], [5] creating the need for numerical studies which is exactly the goal of this work - a thorough numerical study on the hot cracking susceptibility in EBW of CuCr1Zr.

\section{Material And Methods}

Copper has outstanding electrical and heat transfer properties, moderately high-toughness and relatively high strength [6]. Many other common elements are alloyed with copper to improve certain material characteristics such as corrosion resistance or machinability commonly used in a wide range of 
industrial applications. In this specific work, a copper alloy CuCr1Zr is used. This copper alloy contains small amount of chromium and zirconium which contribute to preserve excellent thermomechanical properties of copper at high temperature and increase wear resistance. Due to the very low solubility of $\mathrm{Cr}$ and $\mathrm{Zr}$ in copper, the thermal conductivity is still high. The excellent strength is attributed to the precipitation and particle-dispersion strengthening mechanisms [7]. Chemical composition is represented in Table 1.

Table 1 - CuCr1Zr chemical position in \% [6]

\begin{tabular}{|llllll|}
\hline Fe & Si & Cr & Zr & Other & Cu \\
\hline $0-0,08$ & $0-0,1$ & $0,5-1,2$ & $0,03-0,3$ & 0,2 & Bal. \\
\hline
\end{tabular}

\subsection{Weldability of Cu-alloys}

Welding defects can be defined as imperfections that compromise the usefulness of the welded parts. Defects in weld joints could result in the rejection of parts and assemblies, costly repairs, significant reduction of performance under working conditions and, in extreme cases, catastrophic failures with loss of property and life. Commonly seen defects in copper alloys are related with the presence of certain alloying elements that end up causing porosity due to their low boiling points or high percentage of oxygen in their chemical composition if enough quantities of deoxidizing elements are not present and hot cracking [8]. For EBW experiments performed on CuCr1Zr, a critical problem was the occurrence of hot cracks that were caused by high residual stresses.

\subsection{Existent vs. Proposed Method}

In EBW experiments of CuCr1Zr, hot cracking can be critical. A proposed solution for minimizing tensile residual stresses during solidification was explored. One possible solution to minimizing welding residual stresses actively is using the Low Stress No Distortion technique (LSND) which employs auxiliary cooling or heating sources to manipulate thermal gradients, generating a specific temperature field altering the stresses occurring in the weld zone. A comparison between the magnitude on the residual stresses can be seen in Figure 1, using LSND and conventional welding [5]

These treatment processes are often either time-consuming, can end up increasing the cost and may also change the micro structures and mechanical properties [9]. A different alternative proposes a main welding beam while simultaneous multi-beam preheating on the side of the weld [10], [11]. Zhang et al. [10] found that the main advantages of this process over others, is that other processes need to employ complicated, heavy and costly additional facilities to generate heating or cooling source, while this method uses electromagnetic deflection to generate both welding and pre-heating beams, so there is no need to use auxiliary heating or cooling devices. Another advantage is the fact that due to EBW's characteristics; pre-heating beams can be generated as small as needed, making it possible to produce localized pre-heating areas with any geometric shapes and sizes. Based on these approaches a procedure is presented and investigated in this publication. In this procedure, a Thermally Induced 
Reduction of the Load (TIRL) is applied where an additional Secondary Heat Source (SHS) introduces compressive stresses during the solidification of the weld pool through a local treatment while the Main Heat Source (MHS) associated with the welding process causes melting. The vital parameters of the SHS: the angle, radial distance, power and representative dimension of the SHS are summarized in Figure 2.

One factor at a time (OFAT) method was applied to establish the value ranges for the aforementioned parameters. Subsequently, a systematic experimental approach using DoE was employed to assess statistical significance of the parameters and yield an optimum solution that avoids solidification cracking. A schematic representation of the methodology applied is presented in Figure 3.

The condition whether secondary melting was occurring was verified at all iterative steps. Initially, after having set a parameter window for the power applied, it was possible to adjust the radial distance that ensured maximum introduced compressive stresses whilst no melting caused by the SHS. This was performed successively until a parameter window was defined for every parameter.

\section{Numerical Implementation}

The software Simufact Welding was used for the FEM simulations. It is designed for modeling and simulation of a wide range of thermal joining processes. Furthermore, it allows to model multiple heat treatment processes, variations of cooling and unclamping setups as well as mechanical loading of welded structures making it fit for these types of thermal and thermomechanical simulations. The methodology applied for the numerical implementation was widely based on [12]-[14]. Firstly, the cylinder geometry was modeled using SolidWorks as can be seen in Figure 4.

\subsection{Geometry Discretization}

The detailed geometry is omitted from this publication due to confidentiality reasons. In terms of discretization of the domain, the simplified model built was an assembly of 4 components as is shown in Figure 5 which included a total of 97794 elements - Table 2. In the case of P1 and P4 hexahedral elements were chosen for its improved quality over tetrahedral elements. Tetrahedral elements were chosen for P2 and P3 due to their simple shapes, therefore easing computation for arbitrarily difficult volume and surface integrals in FEM, given that the quality for these parts was not considered as important [15]. The mesh was refined where the heat source's path (P1) is located. The other components (P2, P3 and P4) have a coarse mesh.

Table 2 - Discretization characteristics 


\begin{tabular}{|c|c|}
\hline \multicolumn{2}{|c|}{ P1 - 54492 Elements } \\
\hline Axial & $1 \mathrm{~mm}$ \\
\hline Radial & $2 \mathrm{~mm}$ \\
\hline Tangential & $1 \mathrm{~mm}$ \\
\hline \multicolumn{2}{|c|}{ P2 - 4797 Elements } \\
\hline Element Size & $2.5 \mathrm{~mm}$ \\
\hline \multicolumn{2}{|c|}{ P3 - 4089 Elements } \\
\hline Element Size & $2 \mathrm{~mm}$ \\
\hline \multicolumn{2}{|c|}{ P4 - 34416 Elements } \\
\hline Axial & $3 \mathrm{~mm}$ \\
\hline Radial & $3 \mathrm{~mm}$ \\
\hline Tangential & $1 \mathrm{~mm}$ \\
\hline
\end{tabular}

\subsection{Material Mechanical and Thermophysical Properties}

A similar alternative to CuCr1Zr was used since the material properties of $\mathrm{CuCr} 1 \mathrm{Zr}$ alloy are not available in Simufact Welding material library. Material's properties are described in Table 3.

Table 3 - Material Properties

\begin{tabular}{cccc}
\hline 1) Thermophysical Properties $\left(\mathbf{2 0}^{\circ} \mathbf{C}\right)$ & Unit & CuCr1Zr [6] & Cu_SW \\
\hline Density & $\mathrm{g} / \mathrm{cm}^{3}$ & 8.89 & 8.86 \\
Melting Temperature & ${ }^{\circ} \mathrm{C}$ & 1076 & 1084 \\
Thermal Conductivity & $\mathrm{W} /(\mathrm{m} . \mathrm{K})$ & 170 & 182 \\
Specific Heat Capacity & $\mathrm{J} /(\mathrm{kg} \mathrm{K})$ & 380 & 414 \\
\hline 2) Mechanical Properties $\left(\mathbf{2 0}{ }^{\circ} \mathbf{C}\right)$ & & & 380 \\
Tensile Strength & $\mathrm{MPa}$ & 380 & 300 \\
Yield Strength & $\mathrm{MPa}$ & 300 & $\mathrm{~N} / \mathrm{A}$ \\
Hardness Brinell & $\mathrm{HB}$ & 130 & 129 \\
Young Modulus & $\mathrm{GPa}$ & 128 & \\
\hline
\end{tabular}

The flow curves relating the effective plastic strain with the flow stress extracted from the Simufact library are presented in Figure 6.

\subsection{Heat Source Model}

The software uses the heat source models developed by Goldak et al. [2]. For heat distribution description in deep and narrow welds such as the ones produced by means of electron beam or laser beam, a conical 
heat source model seems to be more suitable. Heat source characteristics can be seen in in Equations (1) and (2).

$$
\begin{aligned}
& Q(x, y, z)=\frac{\eta P}{v} e^{-M \frac{x^{2}+y^{2}}{r_{0}^{2}(x)}} \\
& \text { where } r_{0}=r_{e}+\frac{r_{i}-r_{e}}{z_{i}-z_{e}}\left(z-z_{e}\right)
\end{aligned}
$$

The heat source model parameters: conical upper radius $\left(r_{e}\right)$, conical lower radius $\left(r_{j}\right)$, gaussian parameter $(M)$, conical depth $\left(d_{c}=z_{i}-z_{e}\right)$ were adapted using sensitivity analysis. Thermal simulations were conducted to calibrate process efficiency based on the experimental weld dimensions provided by the company. A short trajectory was chosen, the geometry used for the experiment was a flat plate with $15 \mathrm{~mm}$ of thickness, $400 \mathrm{~mm}$ length and $150 \mathrm{~mm}$ width and the process parameters considered for the experiment were $120 \mathrm{kV}$ voltage, $12.5 \mathrm{~mA}$ beam current and a welding velocity of $20 \mathrm{~mm} / \mathrm{sec}$ An efficiency of $93.5 \%$ was attained and the corresponding weld dimensions numerical (case a.) vs. experimental (case b.) are shown in Figure 7.

A conical heat source was used with an upper diameter and lower diameter of 0,15 and 0,125, respectively, and a conical heat source depth of 1,565. Gaussian parameter was set to 3 . The slight difference between numerical and experimental weld dimensions could be addressed due to slim approximations that were considered when performing sensitivity analysis for the heat source model. Moreover, the process efficiency calibration was fully dependent on the aforementioned analysis.

\section{Results And Discussion}

Having successfully performed an assessment on the MHS such that all influential heat source model parameters were known, it was possible to evaluate the stress distribution conducting thermomechanical simulations. The results for these simulations were exported to an Excel file and compared to the temperature dependent proof strength of the material. The condition for no hot cracking is given by:

$$
\sigma_{\text {stress }}<\sigma_{\text {proof }}
$$

This criterion states that if the stresses were smaller than the admitted proof strength of the material, then hot cracking would not occur. The statistical software Minitab 19 was used to obtain an optimal solution for the SHS parameter configuration minimizing the stress to proof strength ratio.

\subsection{No secondary heat source}

A thermomechanical simulation without the use of a secondary beam was employed and provided an overview on the residual stresses. This evaluation was performed on points selected aligned with the $X-$ axis and $Y$-axis (as is shown in Figure 8) given that the $X$-stress and $Y$-stresses at these points, 
respectively, are entirely equal to the radial stresses (that cause hot cracking). Furthermore, multiple points equally spaced in depth were considered to verify if cracking would, in fact, firstly emerge on the surface of the material.

During many trials it was verified that hot cracking occurred given that the stress applied on the selected points overcame the proof strength at the given temperature. Since the cracking was occurring first in the surface, it was not necessary to check the stress values for the other points below the surface. Figure 9 illustrates the stress values over time on the previously defined surface point. The risk for hot cracking was always during solidification, so the time window was designated accordingly.

To further understand the ratio between the residual stresses and the proof strength and to facilitate the evaluation on the incidence of hot cracking, the ratio was also mapped over time as can be seen in Figure 10. Hence, it can be acknowledged that cracking had occurred since the relation yielded a value greater than 1.

\subsection{OFAT}

Arbitrary values were assumed for an initial condition $\left(d=1 \mathrm{~mm}, P=50 \%\right.$ and $a=0^{\circ}, D$ was set to the same value as considered for the MHS to simplify first simulations). It was concluded that utilizing a SHS with those characteristics too close to the MHS would produce a merge in the fusion zone, melting even more material than intended. To avoid melting by the SHS a sensitivity analysis using the OFAT approach was selected on the Power, keeping all other variables constant. By iteratively lowering the power, it was seen that for this angle and radial distance $\left(a=0^{\circ}\right.$ and $\left.d=1 \mathrm{~mm}\right), 2.5 \%$ was the maximum power that could be employed without secondary melting. After, an assessment keeping the power constant and $a=$ $0^{\circ}$ while adjusting the radial distance was executed, as is presented in Figure 11.

Subsequently, a study on the angle was performed. It was seen that the variation of the angles was very small $\left(\approx 0^{\circ}\right)$, so it is hereafter described as the tangential distance $(\mathrm{dt})$ allowing for easier interpretation. The tangential distance had a clear impact on the results, the closer the heating sources were, the better the results. This made sense since in this case the cooling rate was very high so there was a need to quickly introduce compressive stresses. Finally, multiple tests were conducted for the surface diameter of the SHS, ranging from as low as $D=0.075 \mathrm{~mm}$ up to as high as $D=5 \mathrm{~mm}$, but the results did not vary that much.

\subsection{Design of Experiment (DoE)}

Having gathered understanding of the impact of each variable on the outcome of the simulations, the next step would be to build a parameter window for the DoE. A full factorial design (FFD) was chosen due to its reliability and capacity of giving information on how each factor is correlated with each other [16], [17]. A 3-level full factorial DoE with 4 factors was initially chosen, Table 4. Thus, a total number of 81 simulations were conducted to perform the statistical analysis.

Table 4 - 3-level general full factorial DoE with 4 factors 
Factor Levels Level $1 \quad$ Level $2 \quad$ Level 3

\begin{tabular}{lllll}
\hline $\mathrm{d}[\mathrm{mm}]$ & 3 & 2 & 3 & 4 \\
\hline $\mathrm{P}[\%]$ & 3 & 35 & 40 & 45 \\
\hline $\mathrm{dt}[\mathrm{mm}]$ & 3 & -3 & -1 & 1 \\
\hline $\mathrm{D}[\mathrm{mm}]$ & 3 & 2 & 3 & 4
\end{tabular}

To improve this first trial, Analysis of Variance (ANOVA) was conducted from which resulted the identification and elimination of irrelevant factors and levels [18]-[20]. Hence, D was dropped and a reworked DoE with 3 factors at 2 levels was carried out, as can be seen in Table 5. The tangential distance levels were considered at levels $\mathrm{dt}=3.5 \mathrm{~mm}$ and $\mathrm{dt}=3 \mathrm{~mm}$ and the radial distance levels were $\mathrm{d}$ $=2 \mathrm{~mm}$ and $\mathrm{d}=2.5 \mathrm{~mm}$ since these yielded the best results. The power levels were increased to $45 \%$ and $50 \%$ because increasing the power seemed to produce better results. Nevertheless, increasing it even more would lead to melting by the SHS, so these values were adapted to match both the distances properly.

Table 5 - 2-level general full factorial DoE with 3 factors

\begin{tabular}{llll} 
Factor & Levels & Level 1 & Level 2 \\
\hline $\mathrm{d}[\mathrm{mm}]$ & 2 & 2,0 & 2,5 \\
\hline $\mathrm{P}[\%]$ & 2 & 45 & 50 \\
\hline $\mathrm{dt}[\mathrm{mm}]$ & 2 & $-3,5$ & $-3,0$
\end{tabular}

The statistical results are presented in Table 6. Despite fitting satisfactorily to the provided simulation results (reasonable $\mathrm{R}^{2}$ ), the current model yielded a poor predicted $\mathrm{R}^{2}$.

Table 6 - Initial DoE statistical results

\begin{tabular}{llll}
$\mathbf{S}$ & $\mathbf{R}^{2}$ & $\mathbf{R}^{2}$ (adjusted) & $\mathbf{R}^{2}$ (predicted) \\
\hline 0,2378 & $94,14 \%$ & $58,95 \%$ & $0,00 \%$
\end{tabular}

The modified final DoE was further enhanced from the analysis of the Pareto charts of standardized effects for a significance level of $5 \%$. Therefore, all the unnecessary factors and interactions were also removed (interaction between tangential distance and both radial distance and power - AC and BC - as is presented in Figure 12), and the model obtained had predicted $R^{2}$ of $99,55 \%$. The statistical results are presented in Table 7.

Table 7 - Modified DoE statistical results 


\begin{tabular}{llll}
$\mathbf{S}$ & $\mathbf{R}^{2}$ & $\mathbf{R}^{2}$ (adjusted) & $\mathbf{R}^{2}$ (predicted) \\
\hline 0,01 & $99,97 \%$ & $99,90 \%$ & $99,55 \%$
\end{tabular}

The relations between the response and two other factors were extracted and evaluated through contour charts using the software Minitab 19 [19] and are displayed in Figure 13.

Figure 13a) exhibits the connection between the radial distance of both heat sources and the power applied while retaining the tangential distance constant at $3 \mathrm{~mm}$. The results improved with a relative parabolic increase of power and radial distance - increasing power required a greater distance between both heat sources; whereas a lower power would allow a lesser distance between both heat sources to replicate similar results. This makes sense given that when the temperature is near the melting temperature, the results are worsened. Case b) relates the tangential distance between heat sources and the Power. Conducting experiments with a combination of smaller tangential distances and power applied proven to be advantageous. It can also be concluded that the tangential distance had a bigger impact in comparison to the power. Lastly, case c) presents the effect on the response, considering the radial and tangential distance of both heat sources. The results for this case were extracted keeping the power at a constant value of $50 \%$. Comparably, to the case $b$ ), the radial distance displayed superior influence for lower values of the tangential distance. The response is given by the following regression equation (1).

$$
\mathbf{Y}(\mathbf{P}, \mathbf{d}, \mathbf{d t})=1,43158-0,01807 \mathrm{P}+0,01907 \mathrm{~d}+0,32493 \mathrm{dt}-0,08458 \mathrm{P} \cdot \mathrm{d}+0,08407 \mathrm{P} \cdot \mathrm{d} \cdot \mathrm{dt}
$$

The response optimizer in Minitab allows to identify the combination of input variables that optimize a single response. It calculates an individual desirability for each response and weights each by the importance. These values are combined to determine the composite, or overall, desirability of the response system [19], [21]. In this case, equation (1) was to be minimized. The results showed significant improvement when compared to the first trials, there were multiple feasible solutions from which hot cracking could be mitigated as seen in Table 8. Promising parameter combinations were from 1 to 5 .

Table 8 - Solutions for the minimization of the ratio between stress and proof strength based on the DoE model 


\begin{tabular}{lllll} 
Combination & $\mathbf{P}(\%)$ & $\mathbf{d}(\mathbf{m m})$ & $\mathbf{d t}(\mathbf{m m})$ & $\mathbf{Y}(\mathbf{P}, \mathbf{d}, \mathbf{d t})$ \\
\hline $\mathbf{1}$ & 45,00 & 2,00 & $-3,00$ & 0,9370 \\
\hline $\mathbf{2}$ & 50,00 & 2,50 & $-3,00$ & 0,9390 \\
\hline $\mathbf{3}$ & 49,99 & 2,49 & $-3,00$ & 0,9415 \\
\hline $\mathbf{4}$ & 45,21 & 2,00 & $-3,01$ & 0,9522 \\
\hline $\mathbf{5}$ & 50,00 & 2,47 & $-3,00$ & 0,9529 \\
\hline $\mathbf{6}$ & 45,98 & 2,40 & $-3,00$ & 1,1907 \\
\hline $\mathbf{7}$ & 45,07 & 2,49 & $-3,00$ & 1,3012 \\
\hline $\mathbf{8}$ & 50,00 & 2,00 & $-3,50$ & 1,7199
\end{tabular}

Numerical validation was conducted to gauge the suitability of the statistical model, as a result condition 1 was selected for a final testing as can be seen in Figure 14. The weld dimensions were respected and the peak temperature of the SHS at distinct times throughout the simulation was $1020^{\circ} \mathrm{C}$. Hot cracking also did not seem to occur (stress/proof strength $<1$ ) under these circumstances, so a solution was found and therefore, confirming that the TIRL method is appropriate to avoid hot cracking in CuCr1Zr as can be seen in Figure 15.

\section{Summary And Conclusion}

The main conclusions that arise from the work accomplished in the context of this publication are presented and labeled according to the topics addressed.

- Results improved using the OFAT and DoE procedures, but it is unclear that this solution is a global optimal (principally due to the rapid cooling rate of this particular Cu-alloy);

- The influence of each parameter individually and amongst each other was measured based on the stress level variation. The tangential distance (or angle) had the highest impact in introducing compressive stresses during solidification while the diameter of the SHS had the least effect;

- Smaller distances between heat sources or higher power for the SHS could produce secondary fusion of the material (and possible blend of fusion zones);

- Longer distances between heat sources were proven to be inconsequential, given that solidification for this specific alloy occurred rapidly;

The work performed confirms that numerically it is possible to reproduce electron beam welds in CuCr1Zr whilst preventing the incidence of hot cracking using the TIRL method.

\section{Declarations}

a. Funding (information that explains whether and by whom the research was supported) 
The project was funded by Dobeneck-Technologie-Stiftung

b. Conflicts of interest/Competing interests (include appropriate disclosures)

The assembly dimensions as well as setup details were omitted from the publication due to confidentiality reasons for the entity.

c. Availability of data and material (data transparency)

Not applicable (confidentiality)

d. Code availability (software application or custom code)

Not applicable (confidentiality)

e. Ethics approval (include appropriate approvals or waivers)

Compliance with Ethical Standards

f. Consent to participate (include appropriate statements)

The entity has consented to the submission of the case report for submission to the journal.

g. Consent for publication (include appropriate statements).

The participant has consented to the submission of the case report to the journal.

h. Authors' contributions (optional: please review the submission guidelines from the journal whether statements are mandatory)

Not applicable

\section{References}

[1] G. Schubert, “Electron beam welding-Process, applications and equipment,” 2009.

[2] J. A. Goldak and M. Akhlaghi, Computational welding mechanics. 2005.

[3] G. R. Liu and S. S. Quek, Finite Element Method: A Practical Course. Elsevier Ltd, 2003.

[4] H. Wibowo, M. N. Ilman, P. T. Iswanto, and M. R. Muslih, "Reducing Distortion and Residual Stress Using Dynamically Controlled Low Stress No Distortion and Its Influence on Fatigue Crack Growth Properties of Steel Welded Joints," Trans. Indian Inst. Met., 2019, doi: 10.1007/s12666-018-1469-7.

[5] Q. Guan, "Low stress no distortion welding based on thermal tensioning effects," Avtom. svarka, 2018, doi: 10.15407/as2018.12.05.

[6] J. Freudenberger and H. Warlimont, "Copper and copper alloys," in Springer Handbooks, 2018.

[7] “The Welding Institute," in Quality Technology Handbook, 1984. 
[8] "Weldability of Materials - Copper and Copper Alloys - TWI." https://www.twi-

global.com/technical-knowledge/job-knowledge/weldability-of-materials-copper-and-copper-alloys-023 (accessed Jul. 20, 2021).

[9] S. WANG, Y. HUANG, and L. ZHAO, "Effects of different aging treatments on microstructures and mechanical properties of Al-Cu-Li alloy joints welded by electron beam welding," Chinese J. Aeronaut., 2018, doi: 10.1016/j.cja.2017.07.002.

[10] W. Zhang et al., "Influence of multi-beam preheating temperature and stress on the buckling distortion in electron beam welding," Mater. Des., 2018, doi: 10.1016/j.matdes.2017.11.016.

[11] J. Fan, W. Zhang, B. Qi, and F. Liu, "Influence of Multi-Beam Electron Beam Welding Technique on the Deformation of Ti6Al4V Alloy Sheet," Xiyou Jinshu Cailiao Yu Gongcheng/Rare Met. Mater. Eng., vol. 46, no. 9, pp. 2417-2422, Sep. 2017, doi: 10.1016/s1875-5372(17)30208-4.

[12] M. Chiumenti, M. Cervera, N. Dialami, B. Wu, L. Jinwei, and C. Agelet de Saracibar, "Numerical modeling of the electron beam welding and its experimental validation," Finite Elem. Anal. Des., vol. 121, pp. 118-133, Nov. 2016, doi: 10.1016/j.finel.2016.07.003.

[13] P. Lacki and K. Adamus, "Numerical simulation of the electron beam welding process," in Computers and Structures, Jun. 2011, vol. 89, no. 11-12, pp. 977-985, doi:

10.1016/j.compstruc.2011.01.016.

[14] R. SINGH, S. SINGH, P. K. C. KANIGALPULA, and J. S. SAINI, "Electron beam welding of precipitation hardened CuCrZr alloy: Modeling and experimentation," Trans. Nonferrous Met. Soc. China (English Ed., vol. 30, no. 8, pp. 2156-2169, Aug. 2020, doi: 10.1016/S1003-6326(20)65368-7.

[15] J. N. Reddy, "An Introduction to The Finite Element Method (third Edition)," McGraw-Hill, 2005.

[16] J. Antony, Design of Experiments for Engineers and Scientists. Elsevier Ltd, 2003.

[17] J. Antoy, Design of Experiments for Engineers and Scientists: Second Edition. Elsevier Ltd, 2014.

[18] A. Raj, J. Pratap Kumar, A. Melwin Rego, and I. Sunit Rout, "Optimization of friction stir welding parameters during joining of AA3103 and AA7075 aluminium alloys using Taguchi method," Mater. Today Proc., Mar. 2021, doi: 10.1016/j.matpr.2021.02.246.

[19] “Minitab," Comput. Stat. Data Anal., vol. 1, pp. 55-57, Mar. 1983, doi: 10.1016/01679473(83)90065-8.

[20] M. Arab and M. Zemri, "Optimization of process parameters on friction stir welding of AA 6082-T6 butt joints using Taguchi method," Mech. Mech. Eng., vol. 22, no. 4, pp. 1371-1380, 2018, doi: 10.2478/mme-2018-0107. 

during the fabrication of microchannels for industrial applications," Mater. Today Proc., Jul. 2020, doi: 10.1016/j.matpr.2020.06.134.

\section{Figures}

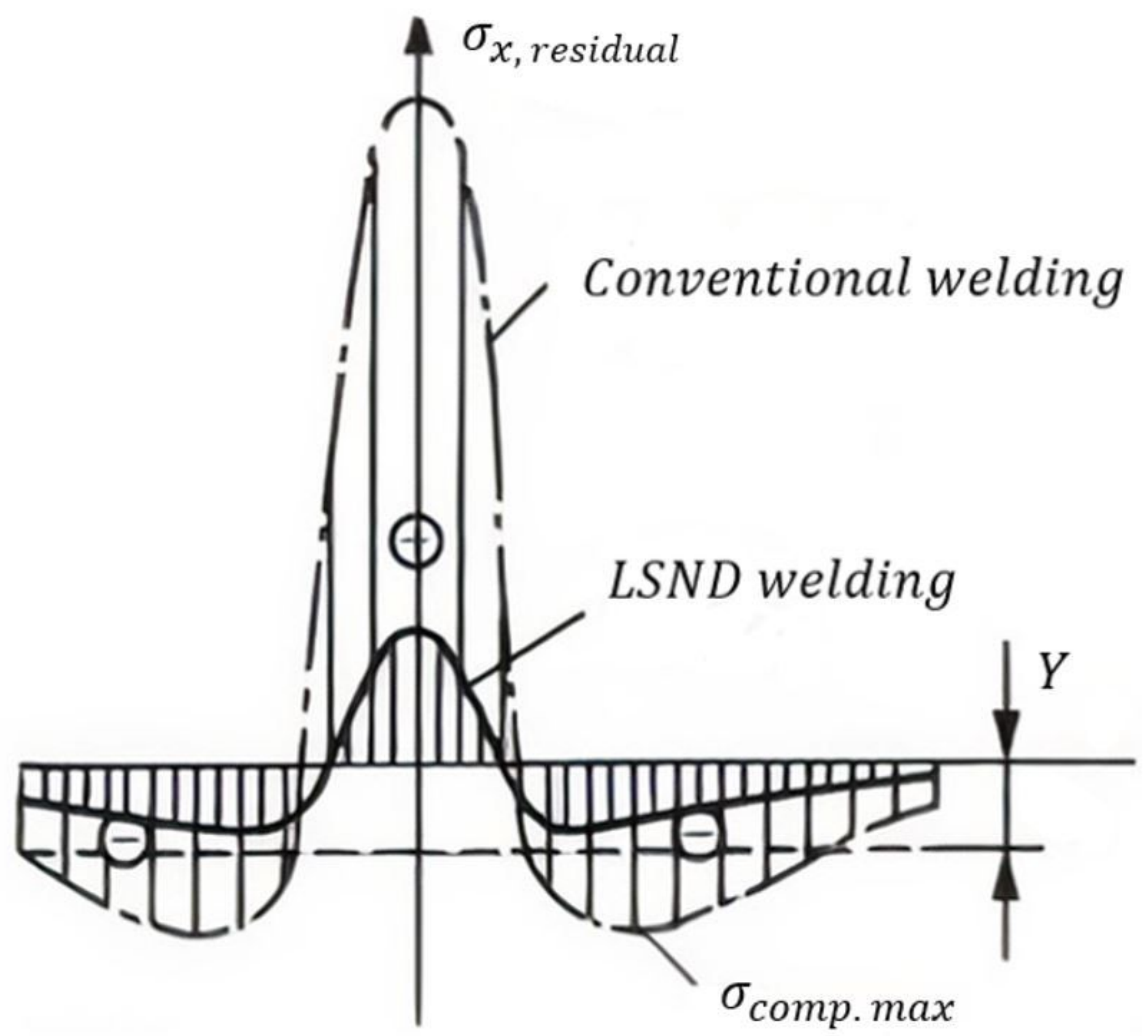

Figure 1

Residual Stresses comparison using LSND vs. conventional welding [5] 


\begin{tabular}{cccc}
\hline $\begin{array}{c}\text { Angle between MHS } \\
\text { and SHS }\left({ }^{\circ}\right)\end{array}$ & $\begin{array}{c}\text { Radial distance } \\
\text { between MHS and } \\
\text { SHS (mm) }\end{array}$ & Power of SHS & $\begin{array}{c}\text { Representative } \\
\text { dimension of SHS: } \\
\text { D }_{\text {SHS }}(\mathbf{m m})\end{array}$ \\
$\alpha$ & d & P & D \\
\hline
\end{tabular}

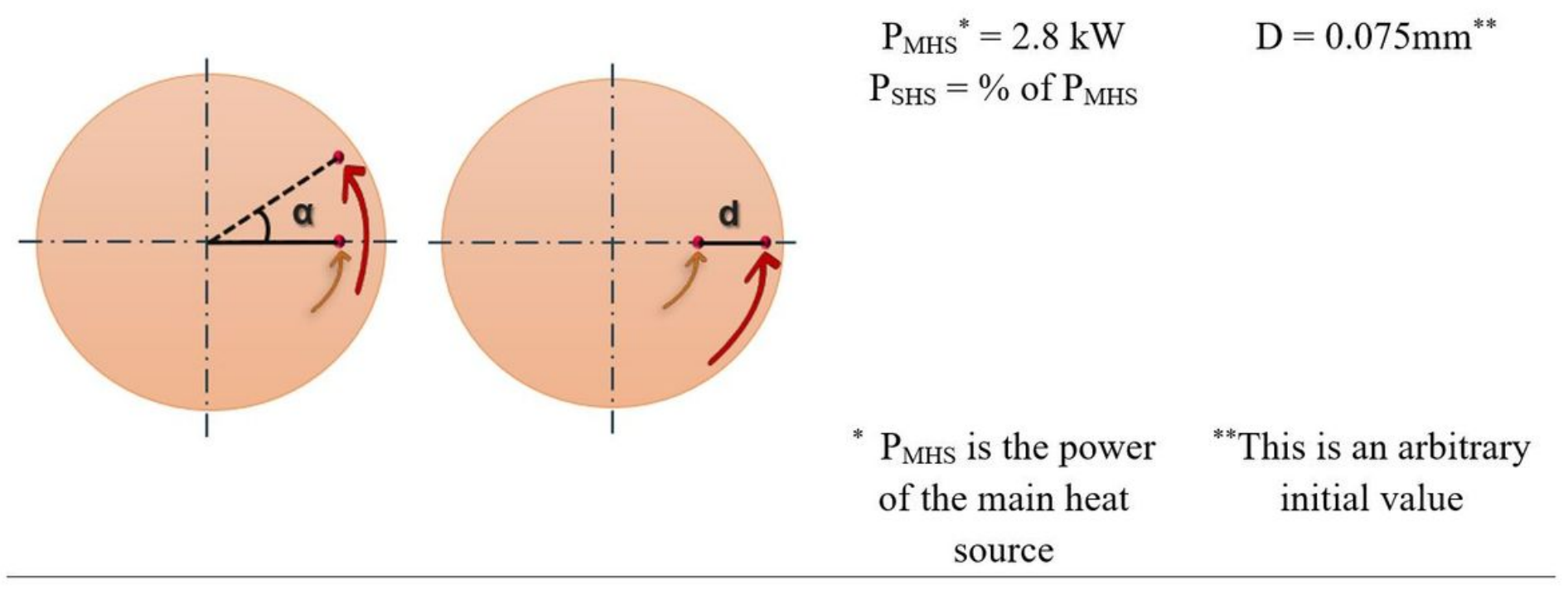

Figure 2

SHS parameters

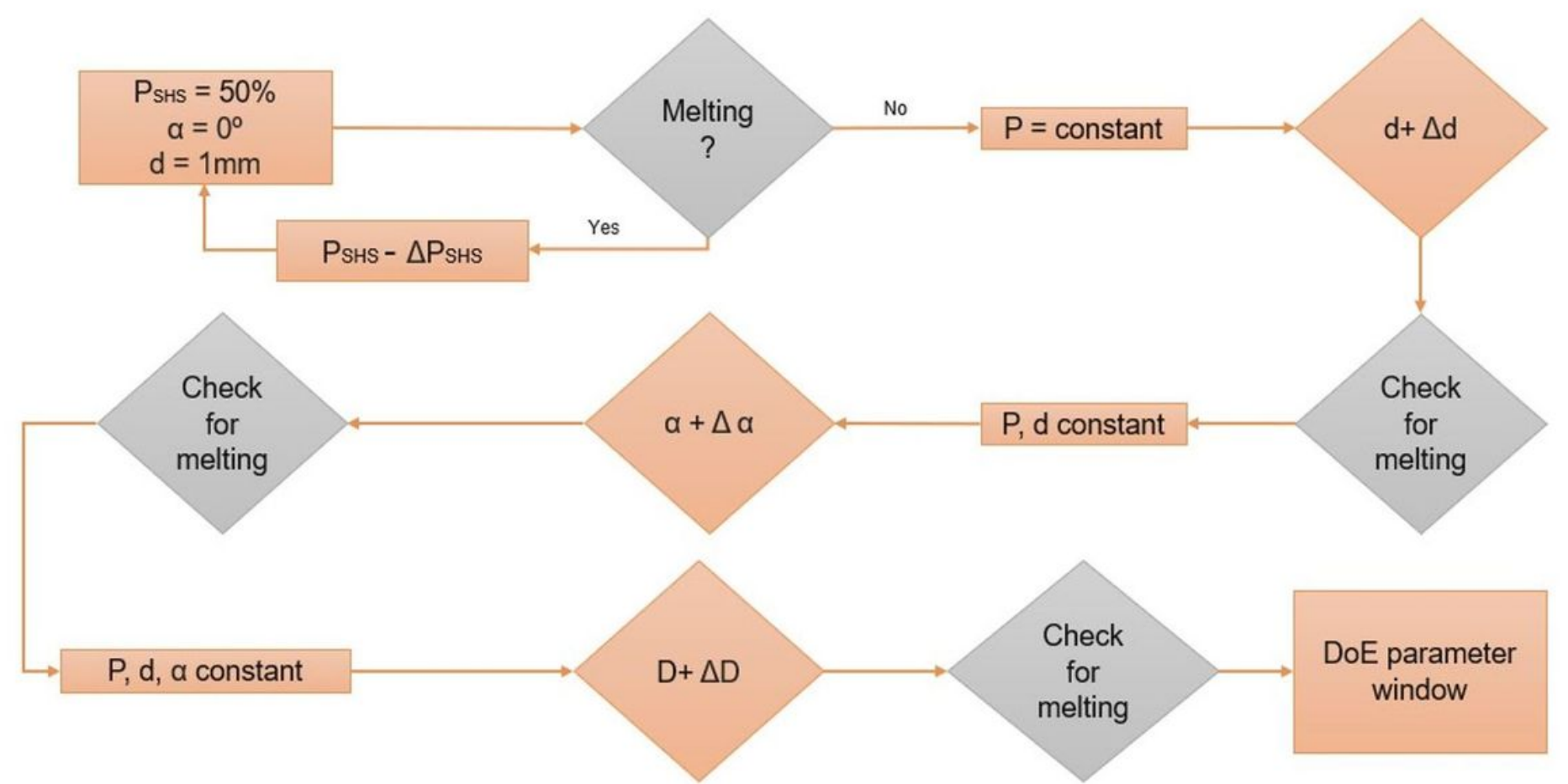

Figure 3 
Flowchart depicting the methodology implemented to define the working range of process parameters

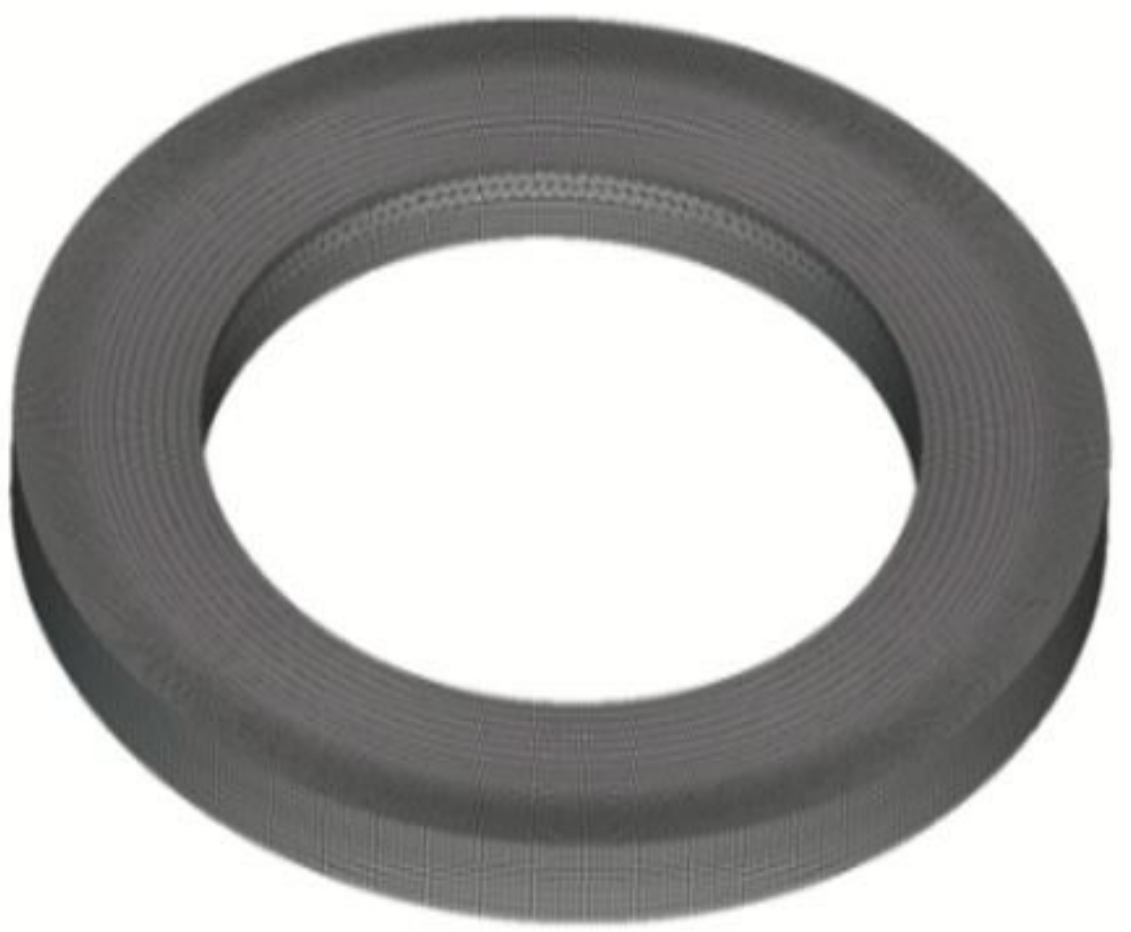

Figure 4

Geometry assembly 


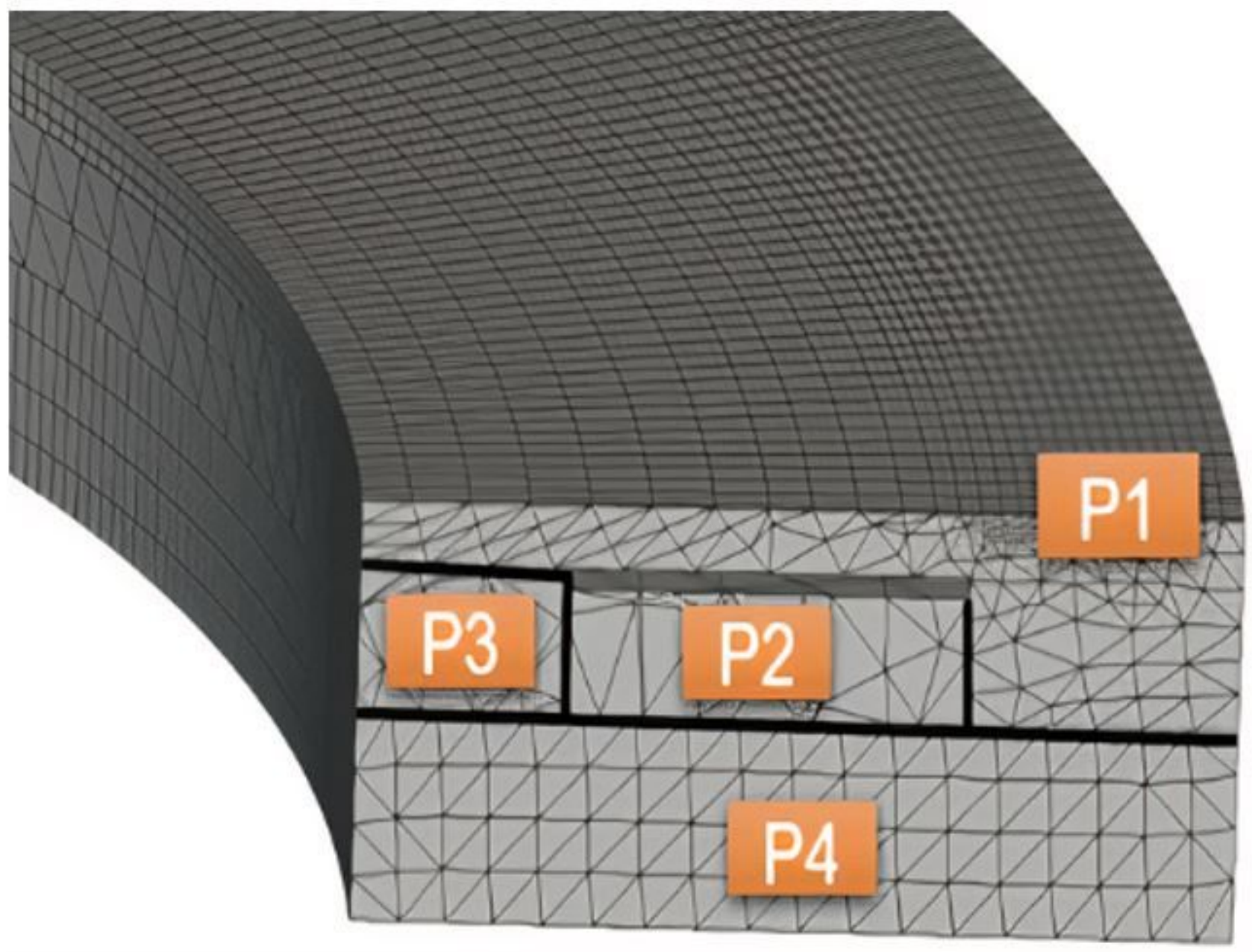

Figure 5

Geometry discretization 


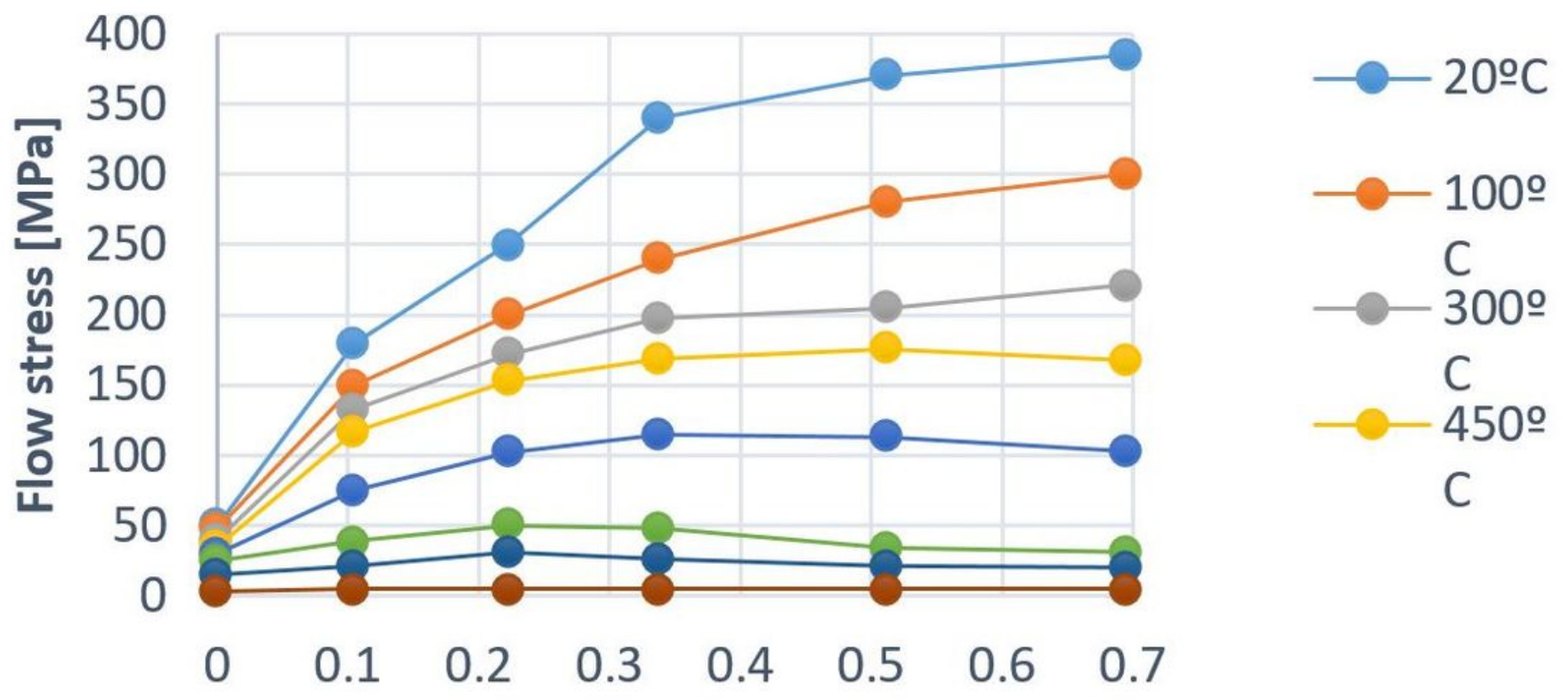

Effective plastic strain

Figure 6

Flow curves of CU_SW from Simufact library
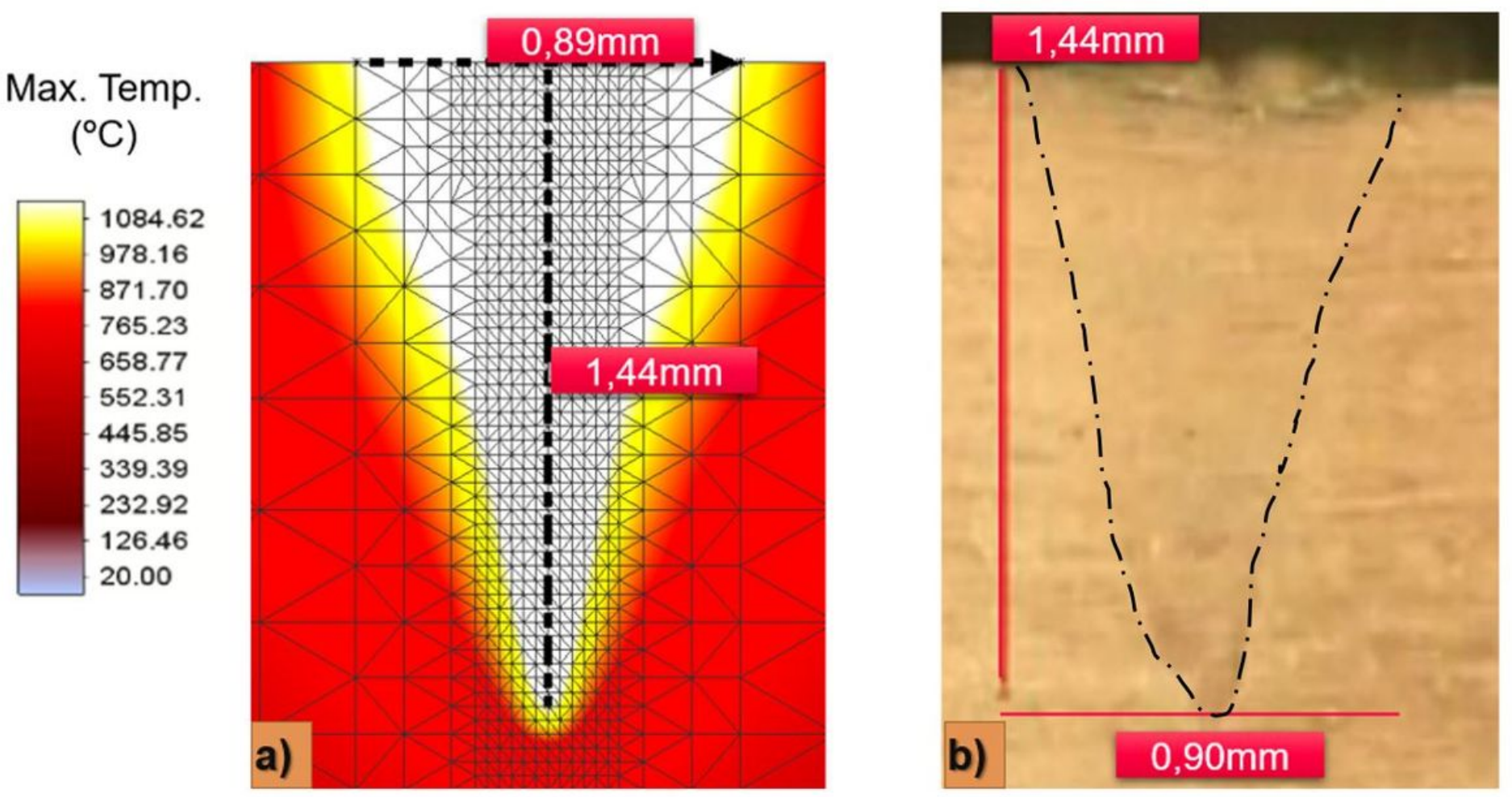

Figure 7

Cross-section highlighting the fusion zone: a) Numerical and b) Experimental result 


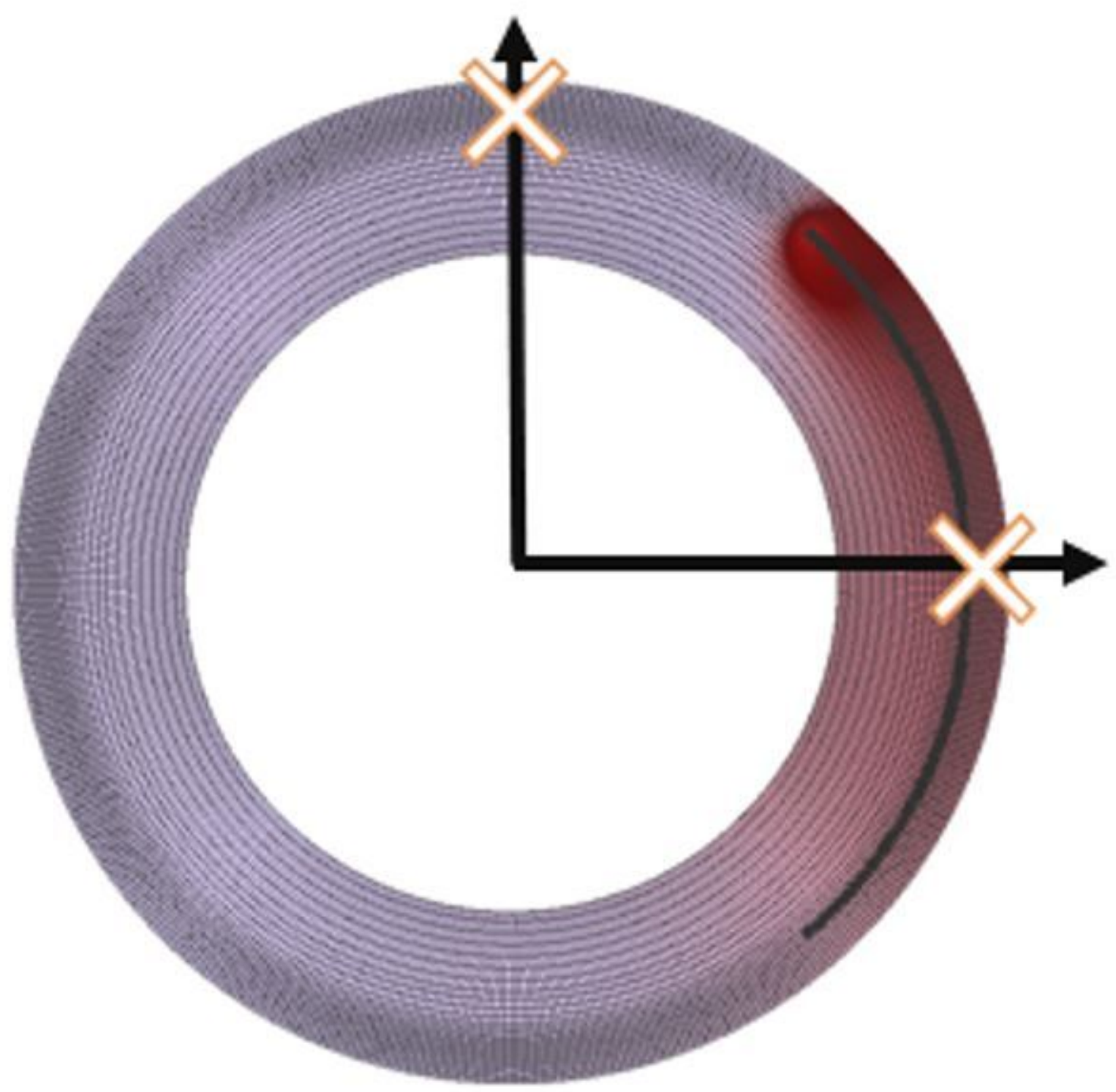

Figure 8

Point selection 


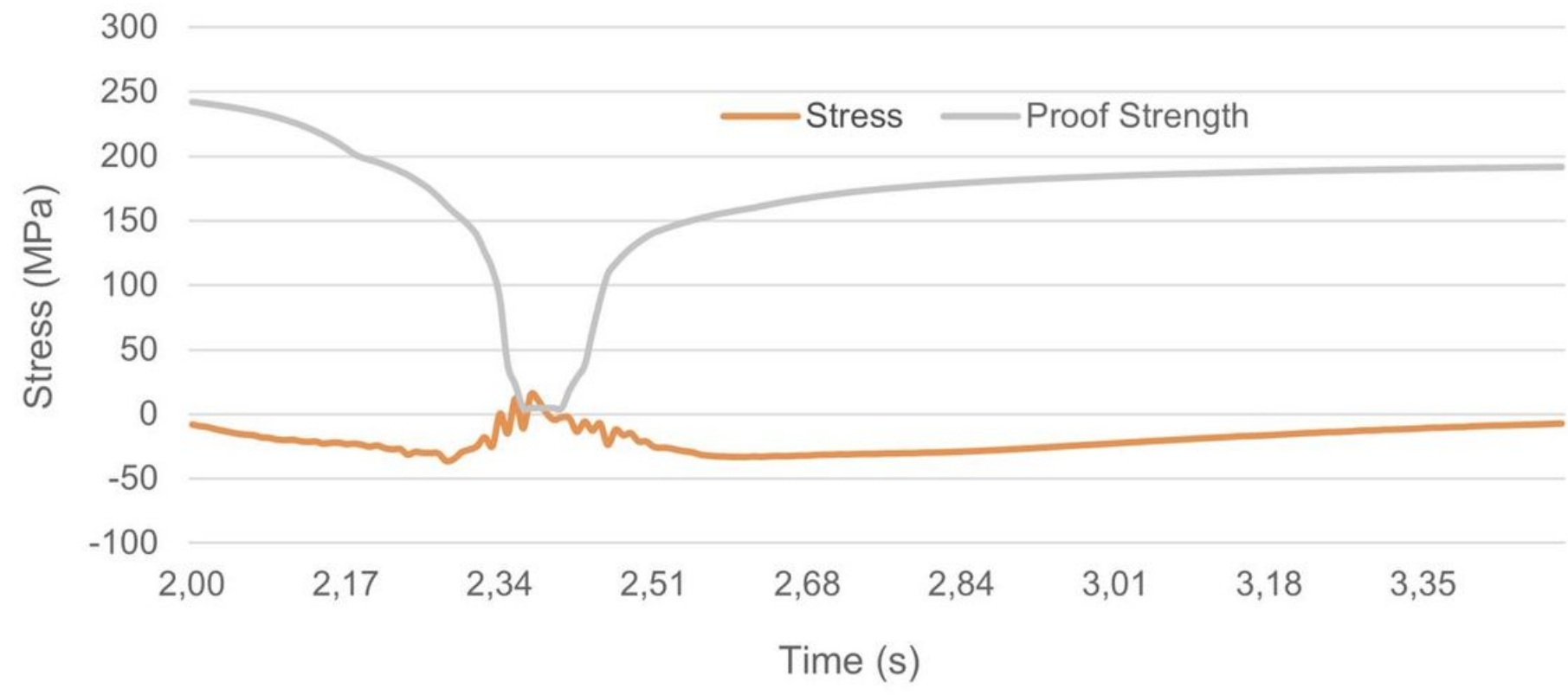

Figure 9

Stress evaluation over time on the surface of a pre-selected point in the weld line

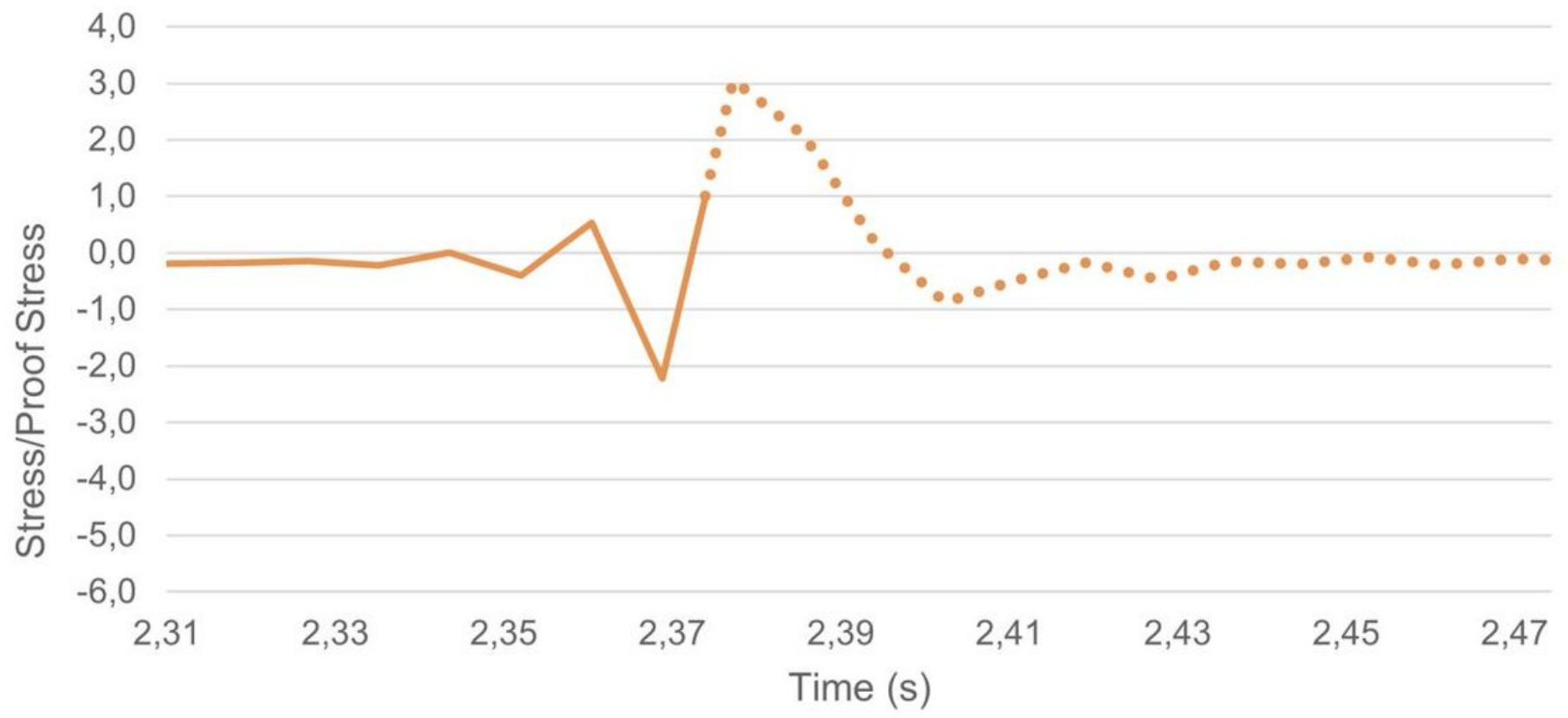

Figure 10

Stress/proof strength over time on the surface of a selected point in the weld line. Dashed line represents case of hot cracking 


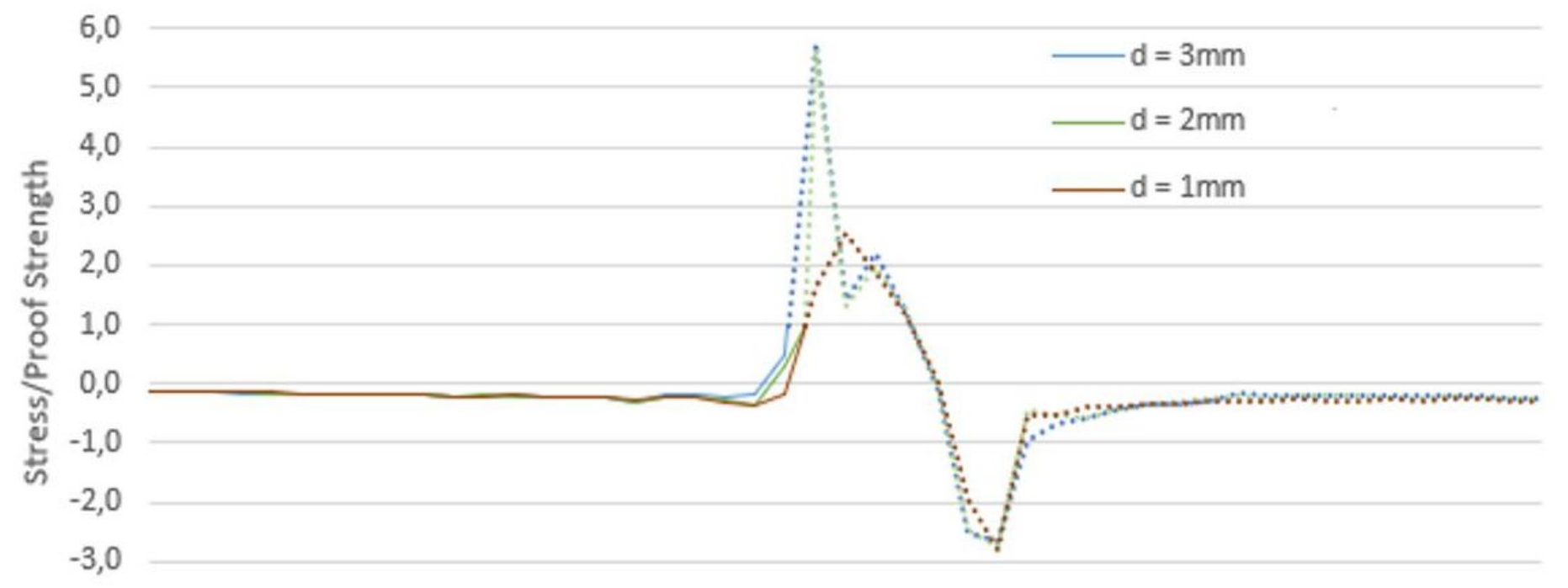

Figure 11

Ratio between stress and proof strength over time for different radial distances using OFAT. Dashed line represents case of hot cracking

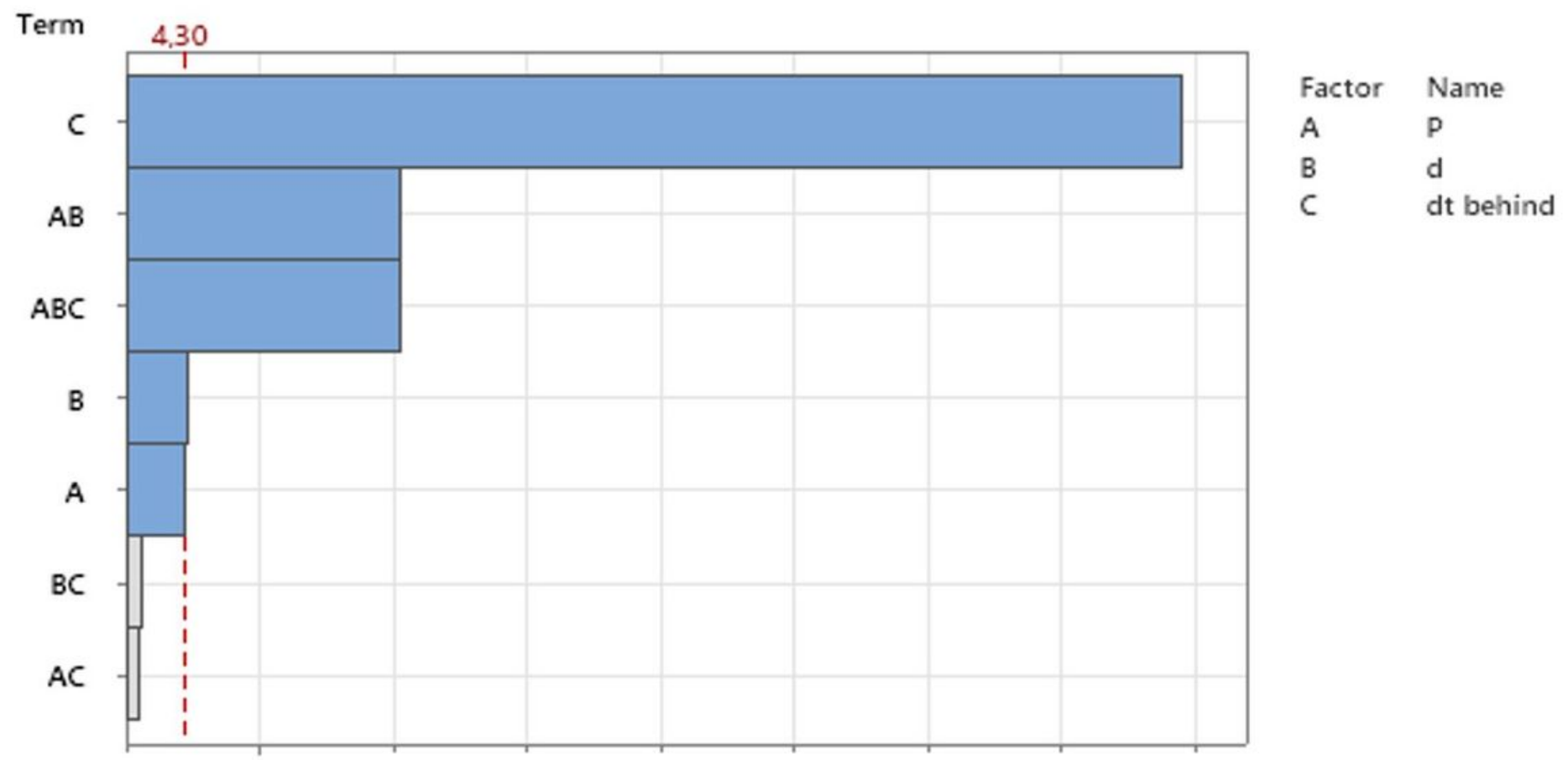

Figure 12

Pareto chart for the standardized response of the modified DoE for $5 \%$ significance level 

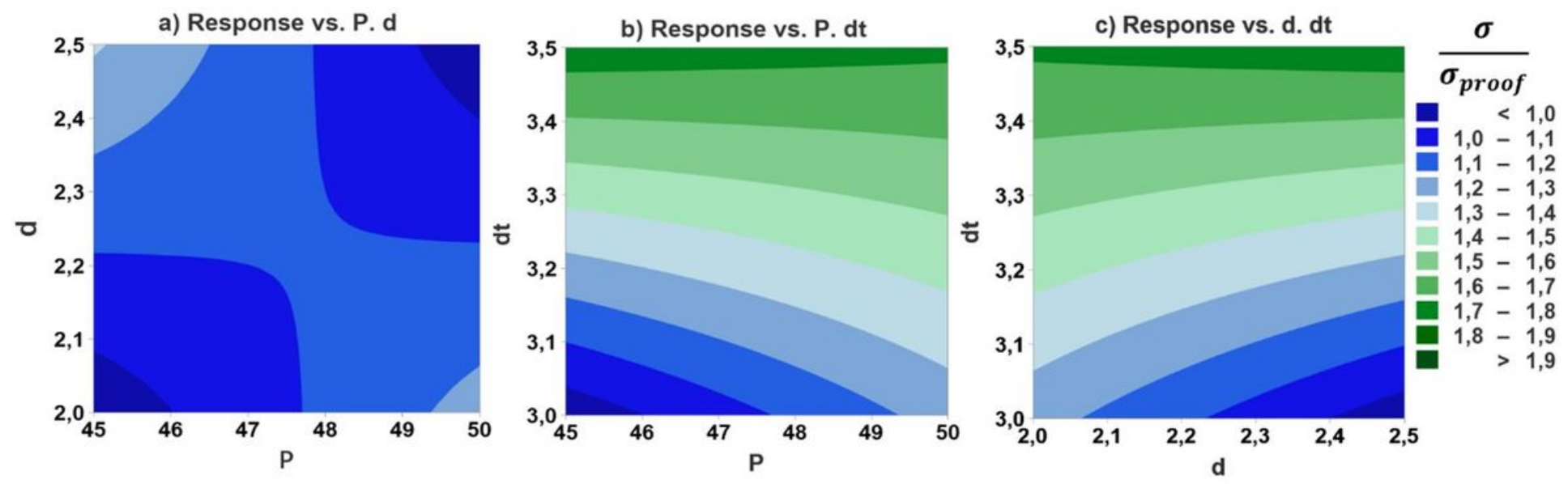

Figure 13

a) Response vs. P. $d t-$ Held value $d t=3 \mathrm{~mm}$; b) Response vs. P. $d t-$ Held value $d=2 \mathrm{~mm}$; c) Response vs. $d$. $d t-$ Held value $P=50 \%$

\section{Max. Temp. $\left({ }^{\circ} \mathrm{C}\right)$}

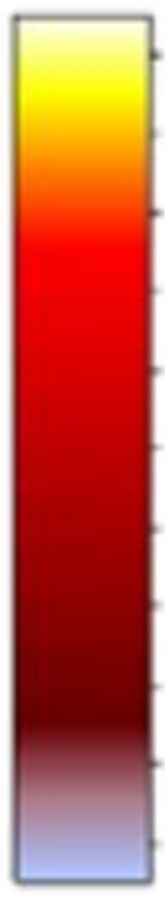

1084.62
978.16
871.70
765.23
658.77
552.31
445.85
339.39
232.92
126.46
20.00

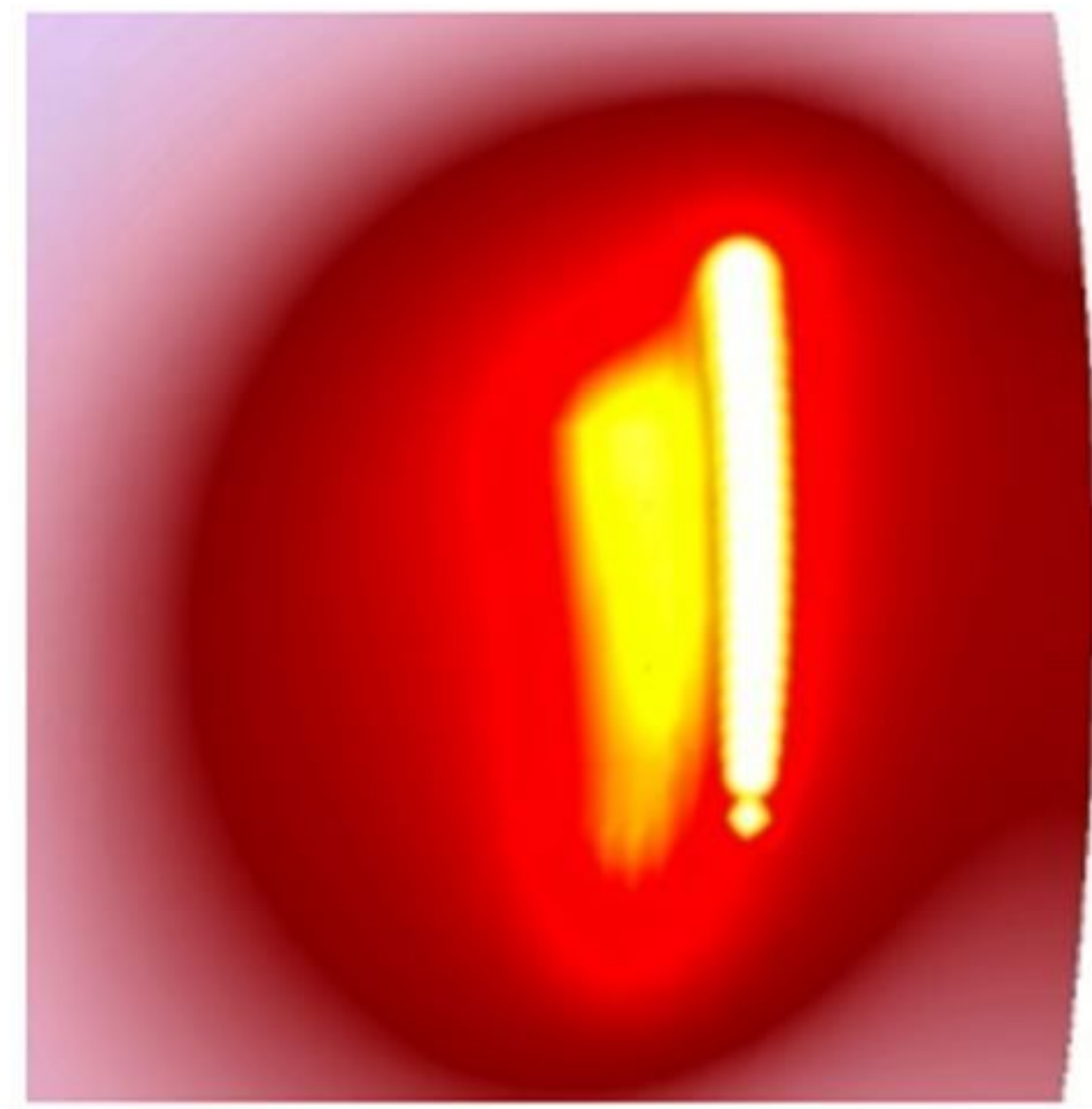

\section{Figure 14}

Peak temperature at different times 


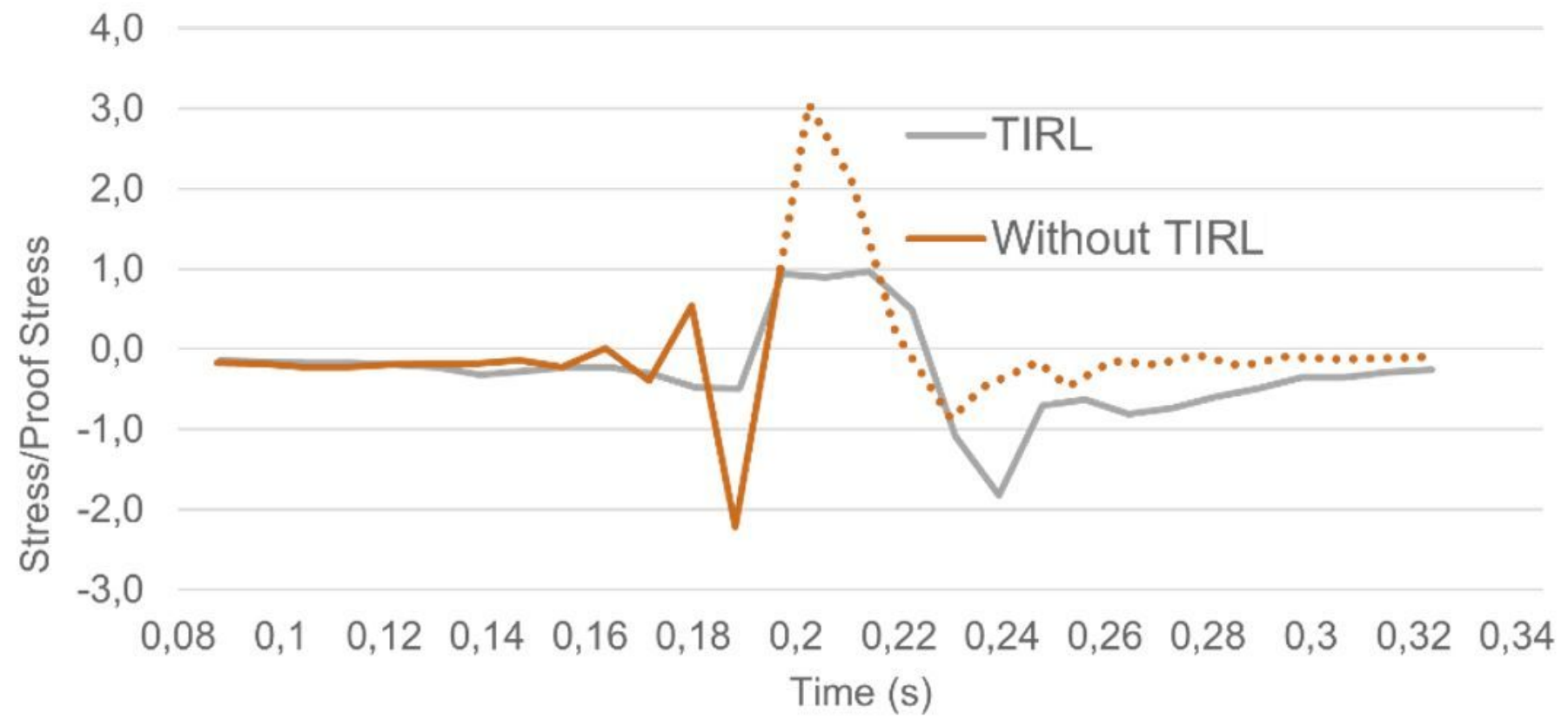

Figure 15

Stress evaluation over time on the surface with and without TIRL. Dashed line represents case of hot cracking

\section{Supplementary Files}

This is a list of supplementary files associated with this preprint. Click to download.

- ManuscriptRCEff.pdf 